\title{
Effect of solvents on metallic and phenolics content in buttercup tree bark vis-a- vis in relation to anthelmintic activity
}

\section{Sravani Singirikonda, Kuntal Das`, Sayani Bhattacharyya, M. Saifulla Khan and Sonam Singh}

Department of Pharmacognosy and Natural Product Chemistry, Krupanidhi College of Pharmacy, Chikkabelandur, Carmelaram Post, Varthur Hobli, Bangalore-560035, Karnataka, India

\section{Article Info}

\section{Article history}

Received 2 April 2021

Revised 20 May 2021

Accepted 22 May 2021

Published online 30 June 2021

\section{Keywords}

Anthelmintic

Cochlospermum religiosum Alston

Correlation

Extraction

Phytoconstituents

Metal ions

\begin{abstract}
The aim of the present study to evaluate metal ion content and total phenolics in various extracts of Cochlospermum religiosum (CR) Alston using two different solvents. The CR is commonly known as Buttercup tree belongs to the family Bixaceae, having many branches. In the present study, ethylacetate, methanol and aqueous solvents are used for the extraction using microwave oven method. All the extracts are tested preliminary for the presence of phytochemicals, followed by TLC for identification. Furthermore, HPLC results estimated the gallic acid content is higher in methanol CR bark extract. The result revealed the presence of carbohydrates, alkaloids, glycosides, tannins, phenolics, flavonoids, and steroidal compounds in aqueous and methanol extracts whereas protein, lipids, and steroids are present in ethyl acetate extract. Content of metal ions ( $\mathrm{Fe}, \mathrm{Mn}, \mathrm{Cu}, \mathrm{Zn}, \mathrm{Co}, \mathrm{Ni}, \mathrm{As}, \mathrm{Hg}, \mathrm{Pb}, \mathrm{Cd}$ ) are determined with atomic absorption spectrophotometer (AAS) and revealed the presence of higher amount of $\mathrm{Zn}$ $(19.13 \mathrm{mg} / \mathrm{g})$ with lower amount of $\mathrm{Mn}(0.06 \mathrm{mg} / \mathrm{g})$ in methanol extract. Other heavy metals are present in negligible quantities. Furthermore, total phenolic content was higher in methanol extract $(28.23 \%)$ extracted for $10 \mathrm{~min}$ than other two extracts. Finally, in vitro anthelmintic activity of extracts was evaluated using reference to standard Albendazole and it showed significant results in concentration dependent manner against Pheretima posthuma, as test worm. The higher result was obtained with methanolic bark extract followed by aqueous extract (extracted with microwave oven for $10 \mathrm{~min}$ with $80^{\circ} \mathrm{C}$ ) and the result was due to presence of polyphenolic compound especially gallic acid $(0.38 \mathrm{~g})$, and also showed a positive correlation with yield and metal ion content.
\end{abstract}

\section{Introduction}

Plants serve mankind in versatile form and are considered as an important and inevitable source of medicaments in our life. All the parts of plants are playing immense role in herbalism. Therefore, plant secondary metabolites like alkaloids, glycosides, phenolics, flavonoids, phytosterols, saponins, resins, tannins an even terpenoids are important products those are stored in various parts of the plant bodies (roots, stems, barks, woods, leaves, fruits, flowers, etc.). Therefore, medicinal virtues of plants are attributed due to presence of the important phytoconstituents such as bioactivities such as antioxidant, anti-inflammatory, antimicrobial, wound healing, anti-Alzheimer, anticancer, etc.

Of late, the Cochlospermum religiosum (CR) Alston (Family: Bixaceae) is well known medicinal tree in India. The tree is commonly known as golden silk cotton tree or butter cup tree because its flowers are bright yellow colored and look like largesized buttercups. The plant is used traditionally as sedative, stimulant, antigonorrheal, and in the treatment of jaundice, cough, trachoma, syphilis, etc. The bark of CR yields gum, also known as

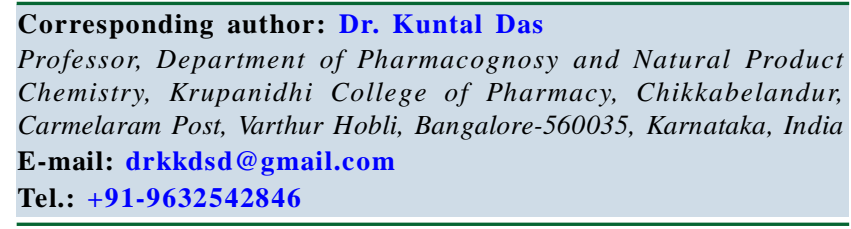

Copyright () 2021 Ukaaz Publications. All rights reserved.

Email: ukaaz@yahoo.com; Website: www.ukaazpublications.com katira. The gum is obtained by stripping the tree bark that contains mainly D-galactose, D-galacturonic acid and L-rhamnose (Vinod et al., 2008). All the parts of the CR tree show many therapeutic activities due to the presence of many bioactive constituents. The leaves contain sterols, triterpenes, saponins, alkaloids, tannins, flavonoids, phenols, glycosides (Ponnamma et al., 2017) and revealed the antibacterial, antifungal, antioxidant activity (Panda $e t$ al., 2016; Buch and Arya, 2017). The flowers are powerful insecticide due to presence of flavonoids, and sterols (Swathi et al., 2019).The bark contains gum which is economically viable with its potential wound healing activity, cholesterol inhibition activity, bioremediation of toxic metals (cadmium, copper, iron, lead, mercury, nickel), and even elicited immunological response (Vinod and Sashidhar, 2011; Hongsing et al., 2012; Girotra and Singh, 2013; Puskuri et al., 2017). Powdered roots are used as tonic and to treat jaundice (Satpure, 2017). Fruit juice is used in dysentery and gonorrhea treatment (Savithramma et al., 2014). The stem bark is used in sores and fistula, bone fractures (Suneetha et al., 2011) with the presence of saponins, tannins, phenolic compounds, alkaloids, phytosterols (Kawde et al., 2015). The bark contains high amount of phenolics and flavonoids and reported as broad spectrum antimicrobial activity (Sasikala et al., 2015). Hence, it is essential to determine the phenolic content in the bark extracts. Thereafter, heavy metals ( $\mathrm{Fe}, \mathrm{Mn}, \mathrm{Cu}, \mathrm{Zn}, \mathrm{Mg}, \mathrm{Cr}, \mathrm{Ni}, \mathrm{Pb}, \mathrm{Hg}$, As, $\mathrm{Co}, \mathrm{Cd}$, etc.) also play an immense role in accumulation of the bioactive constituents in the plant body and alternately help in various therapeutic activities. Some heavy metals are essential for plant 
growth and some are toxic in nature and causes hazardous health complications to humans (Ibrahim et al., 2017; Das et al., 2019). Hence, study on heavy metals is essential to establish complete therapeutic efficacy of plants. But, any literature revealed neither metal ion content nor anthelmintic activity of bark extracts and even any correlation study among them. With the focus of that concept, the present investigation was carried out to establish the potent anthelmintic activity of the CR bark extract and the role of metal ions in the activity by the establishment of the correlation among the phytoconstituents, metal ions and therapeutic activity.

\section{Materials and Methods}

\subsection{Collection and preparation of plant material}

The CR bark was collected from Chikmagalur, Karnataka state and was identified and authenticated by Dr. N. Dhatchanamoorthy, Botanist, Foundation for Revitalisation of Local Health Traditions (FRLHT, Bangalore). After collection, the bark was coarsely powdered using hammer mill and further used for the experimental purpose.

\subsection{Extraction of CR bark}

The coarse CR bark powder ( $25 \mathrm{~g}$ ) was extracted separately with three different solvents, viz., ethyl acetate, methanol and aqueous using microwave oven at three different time intervals $(10,15$ and $20 \mathrm{~min}$ ), using temperature of $80^{\circ} \mathrm{C}, 70^{\circ} \mathrm{C}$ and $60^{\circ} \mathrm{C}$, respectively with microwave input from $300 \mathrm{~W}$ to $100 \mathrm{~W}$, respectively with $100 \mathrm{~W}$ intervals during the extraction and the volume of solvents were fixed of $30 \mathrm{ml}$. The extracts were concentrated by rotary evaporator at $40-45^{\circ} \mathrm{C}$ for $30-45 \mathrm{~min}$. and stored with proper label in small glass bottles in refrigerator at $5^{\circ} \mathrm{C}$. The percentage yield of extracts were calculated separately.

\subsection{Assessment of heavy metals in bark sample}

Dried bark extract was pre treated with concentrated nitric acid in a digestion flask, followed by mixing with acid mixtures $\left(\mathrm{H}_{2} \mathrm{SO}_{4}: \mathrm{HCLO}_{4}\right.$ with ratio of 6:4). Digestion was carried out at $200^{\circ} \mathrm{C}$ until dense white fumes of gases were evolved and finally white residue was obtained. Subsequently, the digested samples were diluted with demineralized water and the volume made up to $50 \mathrm{ml}$. Final solutions were analyzed for various heavy metal contents (Fe, $\mathrm{Mn}, \mathrm{Cu}, \mathrm{Zn}, \mathrm{Co}, \mathrm{Ni}, \mathrm{As}, \mathrm{Hg}, \mathrm{Pb}$, and $\mathrm{Cd}$ ) using an AAS (PerkinElmer model: A Analyst 100; Australia). Air acetylene was used and the concentration of the said metal elements was determined using the standard condition. The wavelengths were selected for the analysis based on the concentration ranges of the sample and the linear relation between the absorbance (AU) and concentration of the determining element. All the samples were checked by carrying out triplicate analyses for the reproducibility of the method used against blank preparation (Das et al., 2019).

\subsection{Pharmacognostical screening}

Phytochemical screenings of CR bark extracts were carried out by different chemical tests for presence of various bioactive agents All the extracts were evaluated for the presence of different phytoconstituents such as alkaloids, glycosides, phytosterols, flavonoids, carbohydrates, and proteins extracted for $10 \mathrm{~min}$ at $80^{\circ}$ C (based on the yield) (Kokate, 2005).

\subsection{Estimation of total phenolics}

Total phenolics content in all the extracts was determined by spectrophotometry using the Folin-Ciocalteu assay. First, $1 \mathrm{ml}$ of CR bark extract was mixed in distilled water $(9 \mathrm{ml})$ and then $1 \mathrm{ml}$ of Folin-Ciocalteu reagent was added to the solution, diluted 1:10 with de-ionized water (Alhakmani et al., 2013). After $10 \mathrm{~min}, 7 \%$ sodium carbonate solution $(10 \mathrm{ml})$ was added and the final volume was made up to $25 \mathrm{ml}$. Standard solutions of gallic acid were prepared at various concentrations $(50,100,150,200,250,300,350$, and $400 \mu \mathrm{g} / \mathrm{ml})$. The mixed solution was kept for $2 \mathrm{~h}$ at $25 \pm 2^{\circ} \mathrm{C}$ and then absorbance was recorded (at $550 \mathrm{~nm}$ ) for both test and standard solutions. A blank sample was prepared for reading corrections. The phenolics content was estimated and expressed as per cent of gallic acid equivalent of extract.

\subsection{Chromatographic identification}

Extracts were evaluated for the presence of particular active compounds through TLC method. The present study was aimed for identification and separation of polyphenolic compounds which were responsible for the anthelmintic activity. Toluene, ethyl acetate and formic acid combination was selected for detection and separation of said compounds (Patel et al., 2017). Further, HPLC analysis was carried out for determination of content of phenolic acid present in the bark extracts after the method validations (specificity, linearity, accuracy, robustness, etc.) as per the standard protocol (ICH, 2005). The mobile phase was prepared by mixing Methanol: Water (60:40). The standard stock solution was prepared by taking $10 \mathrm{mg}$ of gallic acid in $10 \mathrm{ml}$ volumetric flask and made the volume up to $10 \mathrm{ml}$ with methanol (the concentration: $1000 \mu \mathrm{g} /$ $\mathrm{ml}$ ). The column Phenomenex Gemini-NX-5 $\mu \mathrm{m} \mathrm{C} 18$ (2) $110 \AA$ A, LC Column $250 \times 4.6 \mathrm{~mm}$, Ea, was used for the estimation using 1 $\mathrm{ml} / \mathrm{min}$ flow rate of the mobile phase with UV detector at $203 \mathrm{~nm}$ wavelength.

\subsection{Selection of organism for anthelmintic activity}

The present anthelmintic assay was performed on adult earthworm (Pheretima posthuma, belong to class Oligochaeta) due to the anatomical and physiological resemblance of the red worms with the intestinal round worm parasites of human beings. They were collected from the medicinal garden of Krupanidhi College of Pharmacy, Bengaluru and washed with normal water to remove the soil parts and other foreign matters from body and further used for the study. The earthworms of $2-8 \mathrm{~cm}$ in lengths and $0.2-0.5 \mathrm{~cm}$ in width were used for all the experimental protocols. Albendazole $(25 \mathrm{mg} / \mathrm{ml}$ ) was used as a standard solution (prepared by dissolved in DMF), which purchased from local market of Bengaluru and the test solution of extracts $(25,50,100,150,200 \mathrm{mg} / \mathrm{ml})$ were evaluated for anthelmintic activity (Das et al., 2017). The parameters such as time taken for paralysis and death of individual worms were observed during the study. When there was no movement of any part of the body, then time noted for the paralysis condition followed by the death time was noted when no movement of any part of the body and also observed with the fading away of their body colors. The whole investigation was carried out as per the guideline of the Institutional Biosafety and Ethical Committee (Chandrashekhar et al., 2008). 


\subsection{Selection of correlation study}

The yield of the CR bark extract was correlated with the type of the solvent used along with the method of the extraction conditions. Based on the yield, further study was carried out and also correlated with the metallic ion content that showed higher accumulation of the bioactive constituents especially polyphenolic compounds and alkaloids in the bark.

\subsection{Statistical analysis}

Data are expressed as mean \pm SEM from three replications. For anthelmintic activity, one-way ANOVA test followed by Tukey's post hoc test $(p<0.05)$ was used. Correlation coefficient was carried out among the extract and the activities. $\mathrm{P}$ values less than 0.05 were considered to be statistically significant.

Further, design of experiments (DOE) is applied to estimate the effect of time, temperature and polarity of the solvent on anthelmintic activity and yield. A custom design using design expert V 13 was employed to estimate the effect of time of extraction, temperature and polarity of solvents affecting the anthelmintic activity and yield. The independent factors as listed in Table 1 varied in two levels, and the design yielded 21 experimental runs (Table 2).

Table 1: Coded variable in two levels

\begin{tabular}{|l|l|l|l|}
\hline Factors & Low $(-\mathbf{1})$ & Medium $(\mathbf{0})$ & High(+1) \\
\hline Time $(\min )$ & 10 & 15 & 20 \\
\hline Temperature $\left({ }^{\circ} \mathrm{C}\right)$ & 60 & 70 & 80 \\
\hline Solvent (Polarity) & Ethyl acetate & Methanol & Water \\
\hline
\end{tabular}

Table 2: The list of experimental results of the 21 runs

\begin{tabular}{|c|c|c|c|c|c|}
\hline Sr. No. & Temp $\left({ }^{\circ} \mathrm{C}\right)$ & Time (min) & Extracting solvent (Polarity) & Anthelmintic Activity (min) & Yield $(\%)$ \\
\hline 1 & 0 & 1 & 1 & 27.14 & 9.04 \\
\hline 2 & 1 & 1 & -1 & 37.02 & 7.43 \\
\hline 3 & 1 & 1 & 0 & 19.04 & 16.2 \\
\hline 4 & 1 & -1 & 0 & 13.14 & 36 \\
\hline 5 & -1 & 1 & 1 & 31.28 & 8.87 \\
\hline 6 & -1 & -1 & -1 & 21.52 & 18.4 \\
\hline 7 & -1 & 1 & -1 & 28.33 & 17.3 \\
\hline 8 & 0 & 0 & 0 & 15.08 & 28.8 \\
\hline 9 & 1 & 0 & 1 & 30.28 & 7.40 \\
\hline 10 & 1 & -1 & -1 & 27.02 & 9.33 \\
\hline 11 & 0 & -1 & -1 & 30.11 & 10.20 \\
\hline 12 & -1 & 0 & -1 & 29.20 & 10.02 \\
\hline 13 & -1 & 1 & 0 & 18.28 & 17.2 \\
\hline 14 & -1 & 0 & 1 & 34.24 & 12.65 \\
\hline 15 & 1 & 0 & -1 & 38.24 & 7.65 \\
\hline 16 & -1 & -1 & 1 & 30.02 & 11.78 \\
\hline 17 & 1 & 1 & 1 & 27.30 & 12.04 \\
\hline 18 & 0 & -1 & 1 & 29.21 & 10.23 \\
\hline 19 & 0 & 1 & -1 & 33.29 & 9.44 \\
\hline 20 & -1 & -1 & 0 & 18.02 & 19.13 \\
\hline 21 & 1 & -1 & 1 & 17.07 & 24.43 \\
\hline
\end{tabular}

\section{Results}

\subsection{Yield of the extract}

The yield of the CR bark was calculated for all the extracts (aqueous, methanol and ethyl acetate extract) extracted by microwave oven with different time intervals in varied temperature. The solvent amount kept constant at $30 \mathrm{ml}$. The results revealed that the yield of bark was higher in $10 \mathrm{~min}$ extraction time at $80^{\circ} \mathrm{C}$ temp, followed by $15 \mathrm{~min}$ and $20 \mathrm{~min}$ for all the extracts. Among them, methanol extract showed highest yield compared to other solvents (Figure 1). 


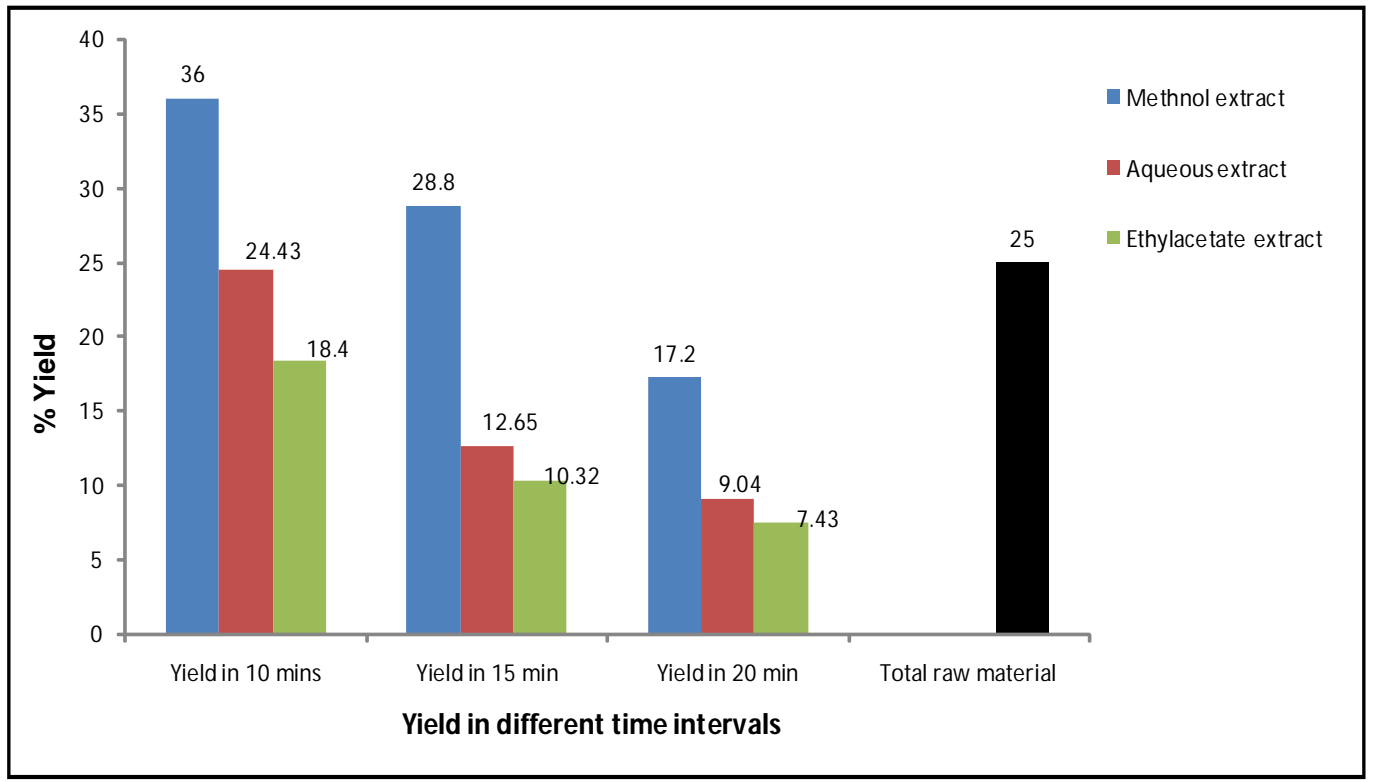

Figure 1: Y-axis: Percentage yield of CR bark extract in different solvents.

Table 3: Metal ion content in CR powdered bark

\begin{tabular}{|c|c|l|l|l|l|}
\hline Metal ions & Wavelength & \multirow{2}{*}{$\begin{array}{c}\text { Slit } \\
(\mathbf{n m})\end{array}$} & & \multicolumn{2}{|c|}{ Microwave assisted (mg/g) extract } \\
\cline { 4 - 6 } & 248.3 & 0.7 & $07.89 \pm 0.21$ & $09.01 \pm 0.11$ & $2.31 \pm 0.03$ \\
\hline $\mathrm{Fe}$ & 279.3 & 0.7 & $00.04 \pm 0.10$ & $00.06 \pm 0.22$ & $0.01 \pm 0.01$ \\
$\mathrm{Mn}$ & 324.8 & 0.7 & $00.09 \pm 0.04$ & $00.13 \pm 0.01$ & $0.02 \pm 0.11$ \\
$\mathrm{Cu}$ & 213.9 & 0.7 & $17.10 \pm 0.20$ & $19.13 \pm 0.21$ & $7.22 \pm 0.12$ \\
$\mathrm{Zn}$ & 240.7 & 0.7 & $00.02 \pm 0.21$ & $\mathrm{ND}$ & $0.03 \pm 0.14$ \\
$\mathrm{Co}$ & 232.1 & 0.7 & $\mathrm{ND}$ & $\mathrm{ND}$ & $0.01 \pm 0.02$ \\
$\mathrm{Ni}$ & 193.7 & 0.7 & ND & ND & ND \\
$\mathrm{As}$ & 253.6 & 0.7 & ND & ND & ND \\
$\mathrm{Hg}$ & 283.3 & 0.7 & ND & ND & ND \\
$\mathrm{Pb}$ & 228.8 & 0.7 & ND & ND & ND \\
$\mathrm{Cd}$ & & & & & \\
\hline
\end{tabular}

- Mean \pm Sem $(n=3) ;$ ND = Not detected

\subsection{Assessment of heavy metals}

Dried extracts of CR bark were analyzed for uptake of elements separately by AAS and the results revealed the presence of some important metal ions in all three different extracts. Varying concentration of $\mathrm{Fe}, \mathrm{Mn}, \mathrm{Cu}$ and $\mathrm{Zn}$ resulted from all the extracts whereas non essential heavy metals such as $\mathrm{Ni}, \mathrm{As}, \mathrm{Hg}, \mathrm{Pb}$ and $\mathrm{Cd}$ were not detected except minute concentration of $\mathrm{Co}$ and $\mathrm{Ni}$ in aqueous $(0.02 \mathrm{mg} / \mathrm{g})$, ethyl acetate $(0.03 \mathrm{mg} / \mathrm{g})$ and solely ethyl acetate extracts $(0.01 \mathrm{mg} / \mathrm{g})$ respectively. The overall result was tabulated in Table-3.

\subsection{Phytochemical screening}

The bioactive compounds varied with the extraction process and also dependent on the type of extracts. Hence, the phytochemical screening tests were carried out for the three different extracts as per the standard method described earlier in methodology section. Based on the higher yield given by all the extracts $\left(10 \mathrm{~min}\right.$ at $\left.80^{\circ} \mathrm{C}\right)$, the results revealed the presence of maximum secondary metabolites in methanol extract followed by aqueous and ethyl acetate extract (summarized in Table 4).

\subsection{Estimation of total phenol}

Based on the chemical test and as per the activity planned, the total phenolic content was estimated in terms of GAE (mg of GA/g of extract, standard curve equation: $\left.\mathrm{y}=0.021 \mathrm{x}+0.174, \mathrm{R}^{2}=0.994\right)$. The total phenolic contents were calculated (\%) using the following linear equation based on the calibration curve of gallic acid and content of higher amount of phenolic showed by methanol extract followed by aqueous and ethyl acetate extracts. Among the extracts, extraction carried out for $10 \mathrm{~min}$ with $80^{\circ} \mathrm{C}$ showed higher values for all the solvents (Table 5). 
Table 4: Various phytochemicals present in different extracts of CR bark

\begin{tabular}{|c|c|c|c|c|}
\hline Phytoconstituents & Various tests & Ethyl acetate extract & Methanol extract & Aqueous extract \\
\hline \multirow[t]{4}{*}{ Alkaloids } & Mayer's test & -- & ++ & + \\
\hline & Dragendorff's test & -- & ++ & + \\
\hline & Wagner's test & -- & ++ & + \\
\hline & Hager's test & -- & + & + \\
\hline \multirow[t]{3}{*}{ Flavonoids } & Shinado test & -- & ++ & + \\
\hline & $\mathrm{FeCl}_{3}$ test & -- & ++ & + \\
\hline & Lead acetate test & -- & + & + \\
\hline Glycoside & Keller killiani test & -- & -- & + \\
\hline \multirow[t]{2}{*}{ Steroids } & Salkowski test & -- & ++ & + \\
\hline & Liebermann burchard test & -- & ++ & + \\
\hline \multirow[t]{2}{*}{ Tannins } & $\mathrm{FeCl}_{3}$ test & -- & + & + \\
\hline & Gelatin test & -- & -- & -- \\
\hline Phenols & $\mathrm{FC}$ reagent test & + & ++ & + \\
\hline Proteins & Biuret test & + & -- & -- \\
\hline Saponins & Foam test & -- & + & ++ \\
\hline \multirow[t]{2}{*}{ Triterpenes } & Salkowski test & -- & ++ & -- \\
\hline & Liebermann burchard test & -- & + & -- \\
\hline
\end{tabular}

$(--)=$ Absent; $(+)=$ present $;(++)=$ Strongly present

Table 5: Total Phenolic content in CR bark extract

\begin{tabular}{|l|l|l|l|}
\hline \multirow{2}{*}{ Extracts } & \multicolumn{3}{|c|}{ Phenolic content $(\boldsymbol{\%})$} \\
\cline { 2 - 4 } & $\mathbf{1 0} \mathbf{~} \mathbf{m i n}$ in $\mathbf{8 0}^{\circ} \mathbf{C}$ & $\mathbf{1 5} \mathbf{~} \mathbf{i n}$ in $\mathbf{7 0}^{\circ} \mathbf{C}$ & $\mathbf{2 0} \mathbf{m i n}$ in $\mathbf{6 0}^{\circ} \mathbf{C}$ \\
\hline Methanol extract & $28.23 \pm 0.031^{* *_{\mathrm{a}}}$ & $24.98 \pm 0.021^{* * \mathrm{~b}}$ & $18.22 \pm 0.011^{* * \mathrm{c}}$ \\
\hline Aqueous extract & $17.54 \pm 0.010^{* *_{\mathrm{c}}}$ & $14.23 \pm 0.011^{* \mathrm{~b}}$ & $12.31 \pm 0.002^{*}$ \\
\hline Ethyl acetate extract & $09.11 \pm 0.012^{* \mathrm{a}}$ & $06.03 \pm 0.042^{\mathrm{ns}}$ & $03.11 \pm 0.013^{\mathrm{ns}}$ \\
\hline
\end{tabular}

Mean \pm SD ( $=3)$; One way ANOVA study followed by Tukey’s post hoc test. Significant level, ${ }^{*} p<0.05$ ${ }^{* *} \mathrm{p}<0.01$; Means with different superscript letter $(\mathrm{a}, \mathrm{b}, \mathrm{c})$ differ significantly $(p<0.05)$ from one another. "ns" = non significance.

\subsection{Chromatographic identification and estimation}

Based on the phytochemical screening, further TLC was performed for the identification and separation of the active components. It was observed that toluene, ethyl acetate and formic acid with the ratio of 7: 5: 1 showed the better separation of phenolic compound, i.e., gallic acid. In case of methanol extract, gallic acid was visible prominently (under UV $366 \mathrm{~nm}$ ) with the Rf value of 0.42 whereas less visible in ethyl acetate extract (Figure 2).

Further, quantification of the constituents through HPLC was performed. The methanolic extract showed more content of gallic acid $(0.38 \mathrm{~g} / 100 \mathrm{~g})$ which were higher than aqueous extract $(0.19 \mathrm{~g} /$ $100 \mathrm{~g}$ ) when experiment was carried out UV at $203 \mathrm{~nm}$. The retention time (Rt) for the gallic acid in methanolic extract showed same as per standards (Figures 3a and $b$ ) with the value of $3.105 \mathrm{~min}$ (Table 6).

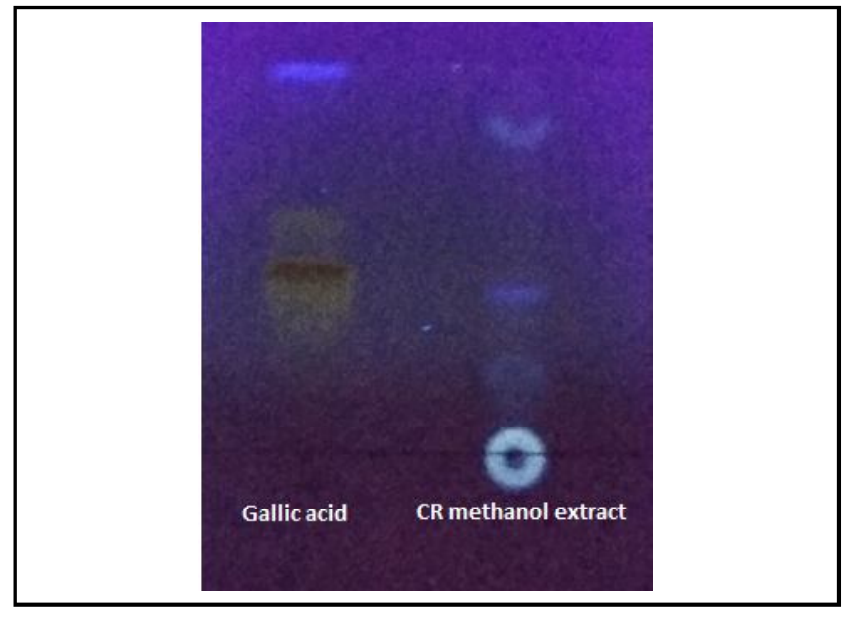

Figure 2: TLC of CR extract with standard gallic acid. 


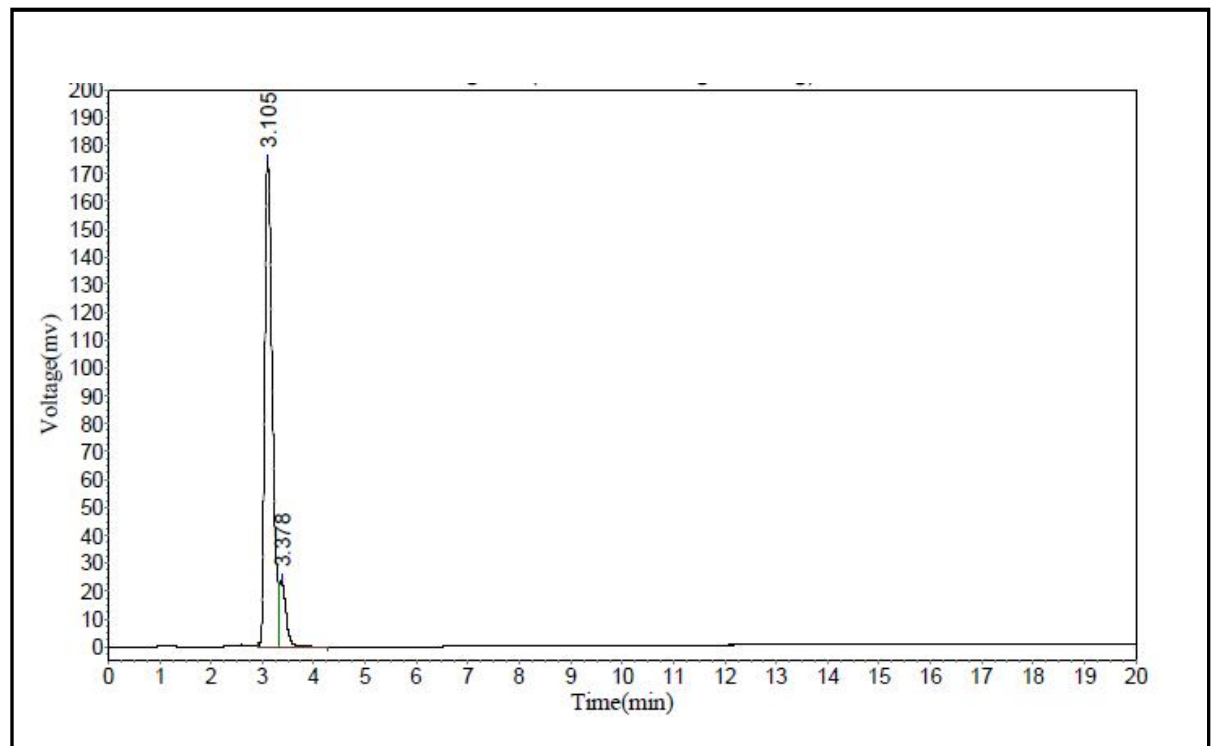

Figure 3a: Standard gallic acid (96\% purity).

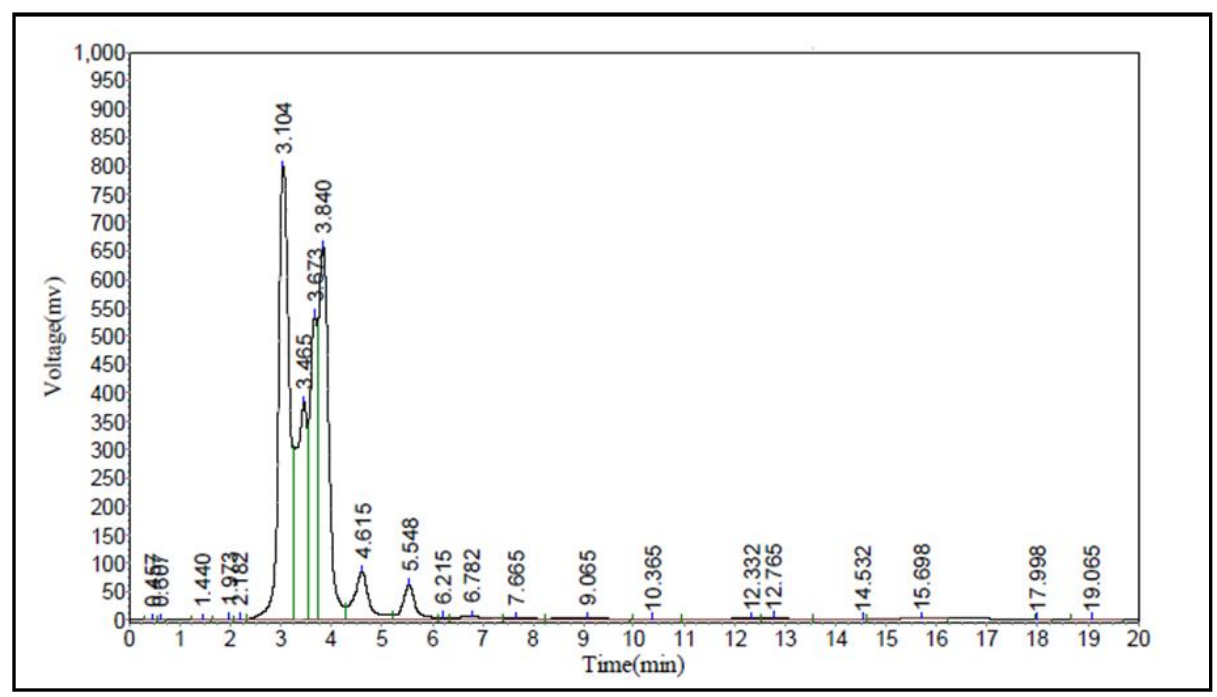

Figure 3b: HPLC of methanol CR bark extract for presence of gallic acid.

Table 6: Gallic acid content in CR bark extract

\begin{tabular}{|l|c|c|c|}
\hline \multirow{2}{*}{ Extracts } & \multicolumn{3}{|c|}{ Gallic acid content $(\mathbf{g} / \mathbf{1 0 0} \mathbf{~ g})$} \\
\cline { 2 - 4 } & $\mathbf{1 0} \mathbf{~} \mathbf{m i n}$ in $\mathbf{8 0}^{\circ} \mathbf{C}$ & $\mathbf{1 5} \mathbf{~ m i n}$ in $\mathbf{7 0}^{\circ} \mathbf{C}$ & $\mathbf{2 0} \mathbf{~ m i n}$ in $\mathbf{6 0}^{\circ} \mathbf{C}$ \\
\hline Methanol extract & 0.38 & 0.34 & 0.21 \\
\hline Aqueous extract & 0.19 & 0.12 & 0.09 \\
\hline Ethyl acetate extract & 0.08 & 0.03 & 0.01 \\
\hline
\end{tabular}

\subsection{Anthelmintic activity}

The higher yielded extracts, i.e., methanol, aqueous and ethyl acetate CR bark extracts of $10 \mathrm{~min}$ in $80^{\circ} \mathrm{C}$, were selected based on the content of phenolic acid and the anthelmintic activity was carried out. The result observed in terms of paralysis and death of the organisms. All the extracts showed activity but methanol extract showed higher activity in lower time than other extracts but the time taken for death of animals was little higher than the standard albendazole $(25 \mathrm{mg} / \mathrm{ml})$. Overall the activity showed concentration dependent for all extracts. Among them, concentration at $200 \mathrm{mg} /$ $\mathrm{ml}$ (methanol extract) showed higher inhibition of parasite movement (9.24 $\mathrm{min})$, followed by death $(13.14 \mathrm{~min})$ and the result showed more significant as compared to control and standard (Figure 4). 


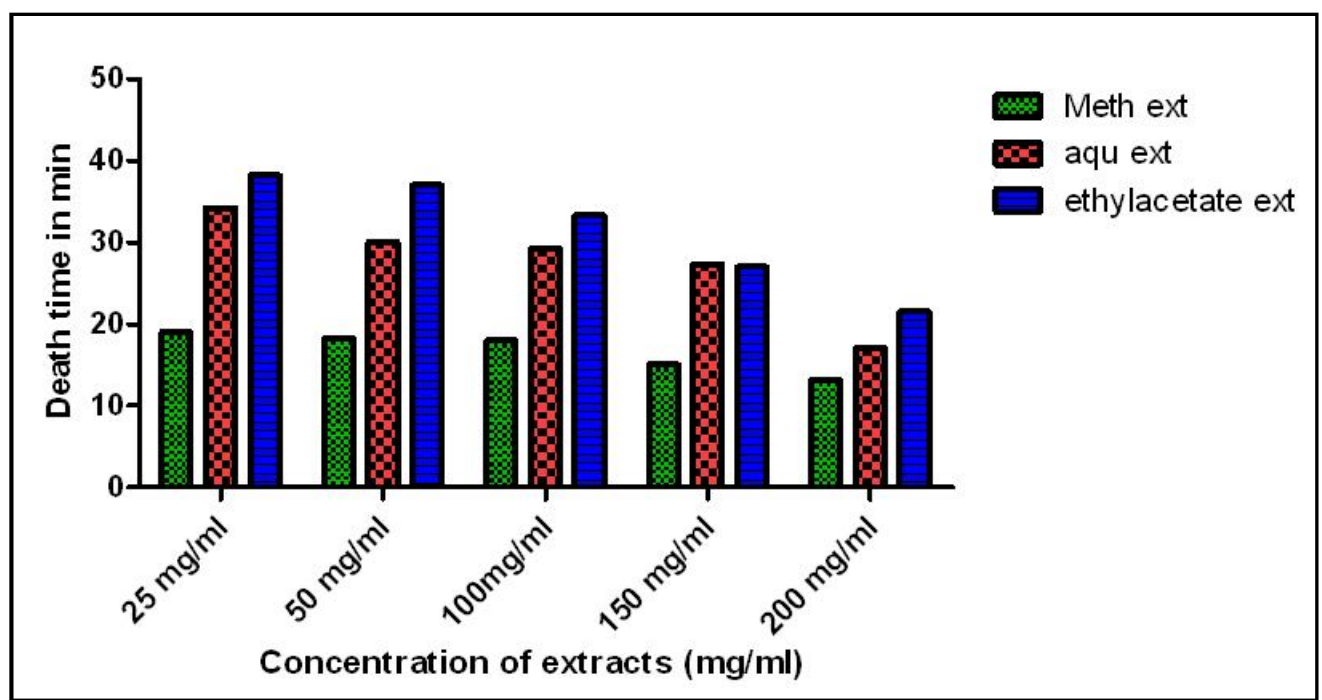

Figure 4: Anthelmintic activity of CR bark extracts (death study shown).

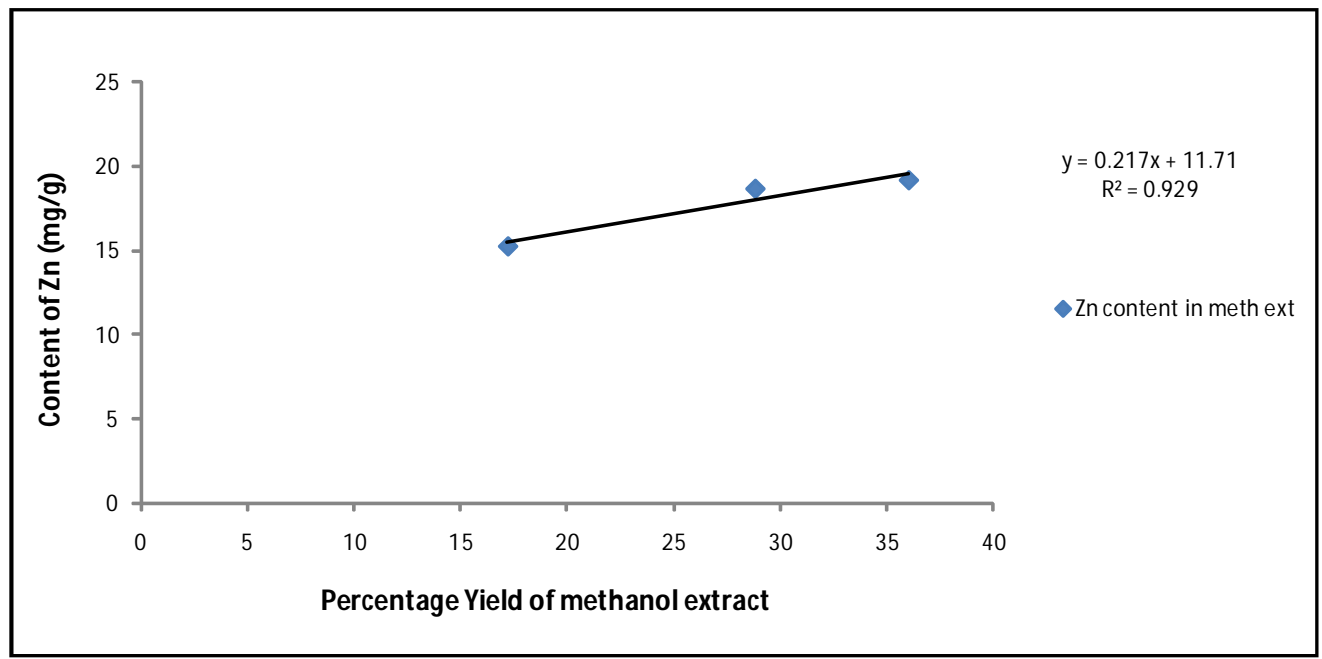

Figure 5a: Zn content in methanol extract.

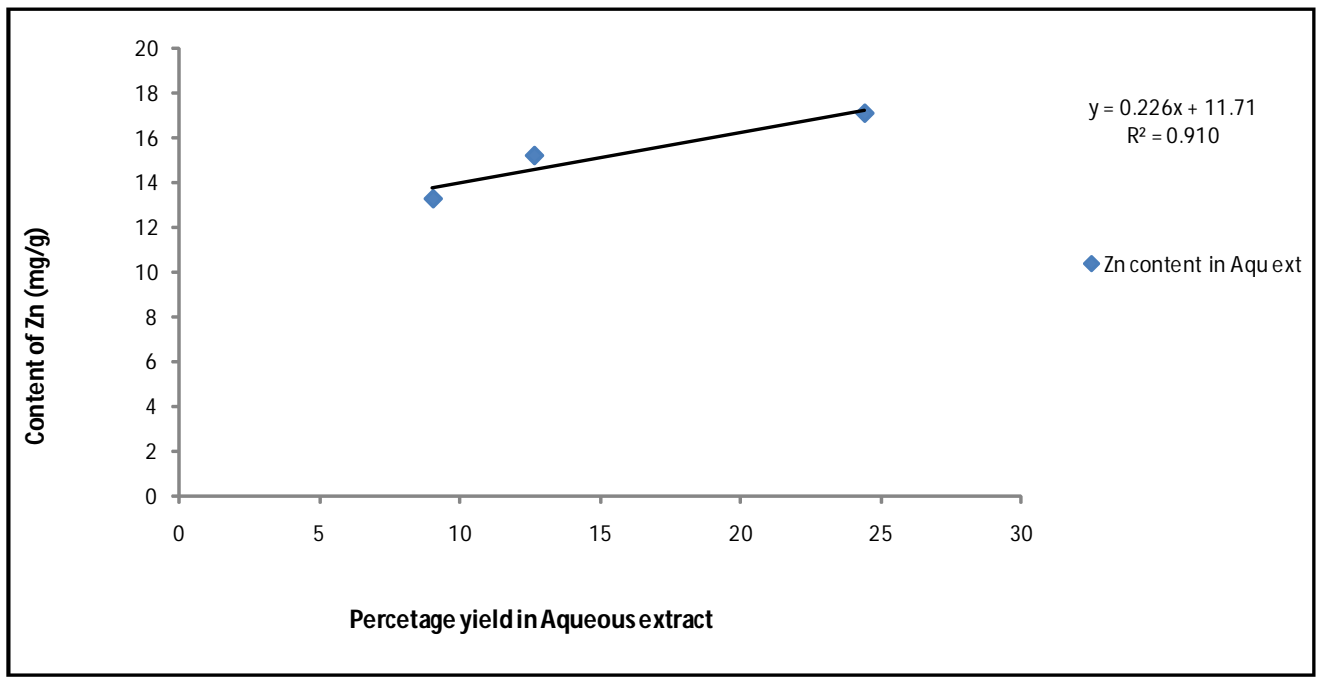

Figure 5b: Zn content in aqueous extract. 


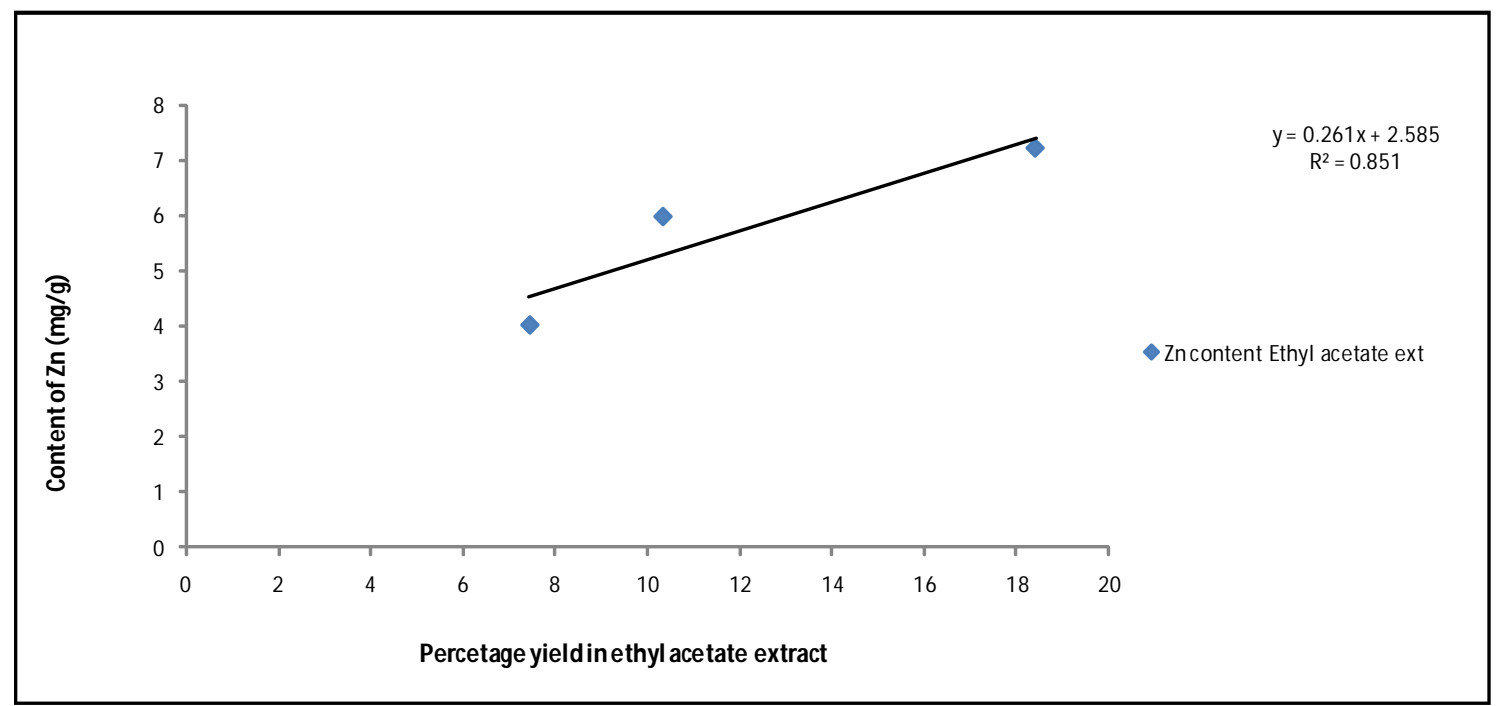

Figure 5c: $\mathrm{Zn}$ content in ethyl acetate extract.

\subsection{Correlation study}

The percentage yield of the extracts from different time intervals were calculated and further correlated with the heavy metals mainly with content of $\mathrm{Zn}$ estimated from the same. It was revealed that amount of heavy metals showed positive correlation with the percentage yield of the extracts (Figures 5a, b, and c) but among all methanol extract showed higher correlation.
Further, percentage yield was correlated with percent content of total phenolic and revealed significant positive correlation. Among them methanol extract showed highest correlation with percentage total phenolics $\left(0.984^{*}\right)$ than the others two extracts (Table 7 ), but all were showed significant positive correlation. The leverage graphs are presented in Figure 6 which clearly indicated the responses were affected by the time temperature and type of solvents. The response surface diagram was depicted in Figures $7 a$ and $7 b$.

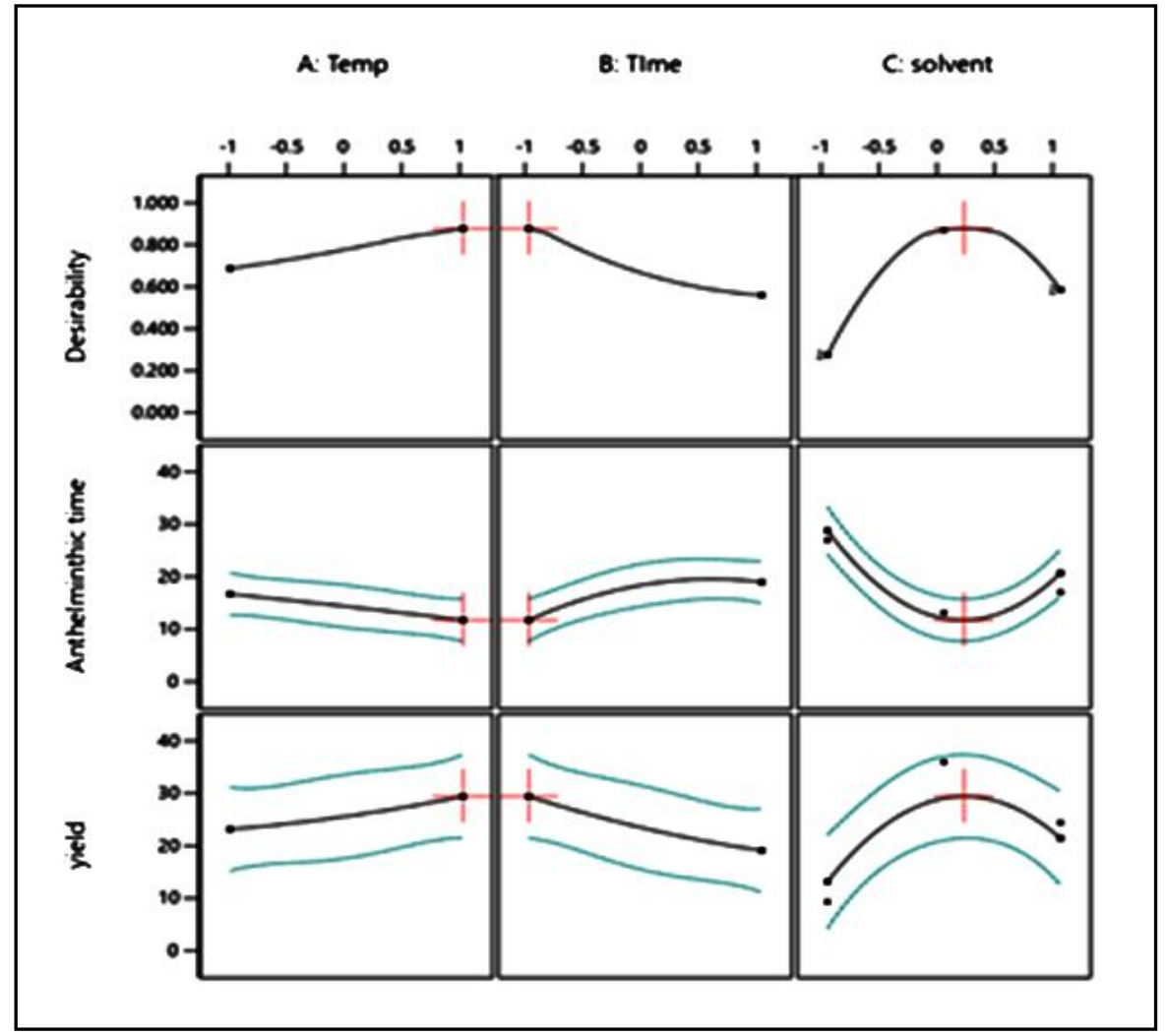

Figure 6: The leverage graphs. 
Table 7: Correlation coefficient between percentage yield and percentage phenolic content

\begin{tabular}{|l|c|c|c|c|c|c|}
\hline & $\begin{array}{c}\% \text { yield } \\
\text { Meth }\end{array}$ & $\begin{array}{c}\% \text { phenol } \\
\text { content } \\
\text { (Meth) }\end{array}$ & $\begin{array}{c}\% \text { yield } \\
\text { Aqu }\end{array}$ & $\begin{array}{c}\text { \% phenol } \\
\text { content } \\
\text { (Aqu) }\end{array}$ & $\begin{array}{c}\% \text { yield } \\
\text { Ethyl } \\
\text { acetate }\end{array}$ & $\begin{array}{c}\text { \% phenol } \\
\text { content } \\
\text { (Eth Acet) }\end{array}$ \\
\hline$\%$ yield Meth & 1 & & & & & \\
\hline$\%$ phenol content (Meth) & $0.984^{*}$ & 1 & & & & \\
\hline$\%$ yield Aqu & $0.954^{*}$ & 0.909 & 1 & & & \\
\hline$\%$ phenol content (Aqu) & $0.968^{*}$ & $0.993^{*}$ & 0.918 & 1 & & \\
\hline$\%$ yield Ethyl acetate & 0.966 & 0.928 & $0.999^{*}$ & 0.931 & 1 & 1 \\
\hline$\%$ phenol content (Eth Acet) & $0.983^{*}$ & 0.938 & $0.984^{*}$ & 0.922 & 0.913 & 1 \\
\hline
\end{tabular}

Significant at $* p<0.05$.

Thereafter, a custom design was evaluated at $p<0.05$ and the model was found to be significant as presented in Table 8 .

Table 8: Statistical data analysis of yield Vs anthelmintic activity

\begin{tabular}{|l|c|c|c|c|c|c|c|}
\hline Response & Source & Sum of squares & df & Mean square & F-value & p-value & \\
\hline Anthelmintic time & Quadratic model & 952.40 & 9 & 105.82 & 13.46 & $<0.0001$ & Significant \\
\hline yield & Quadratic model & 816.61 & 9 & 90.73 & 2.95 & 0.0472 & Significant \\
\hline
\end{tabular}

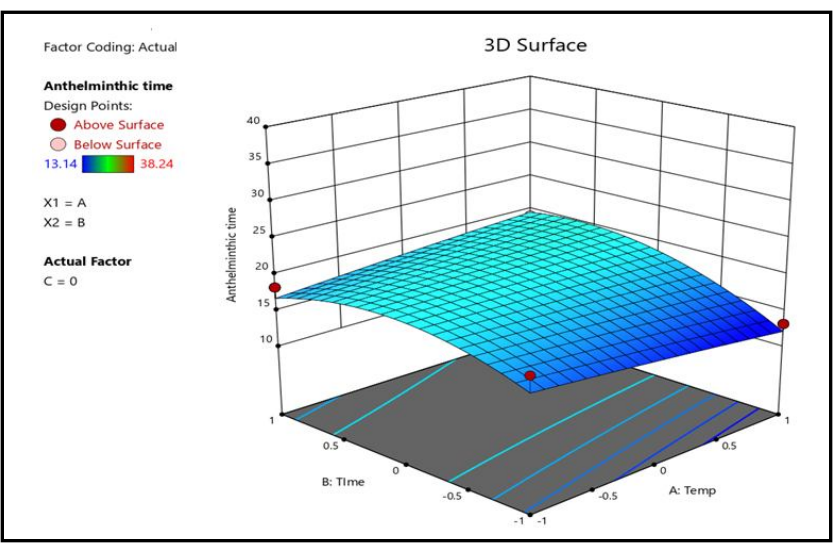

Figure 7a: Response surface diagram for yield variation with respect to time and temperature.

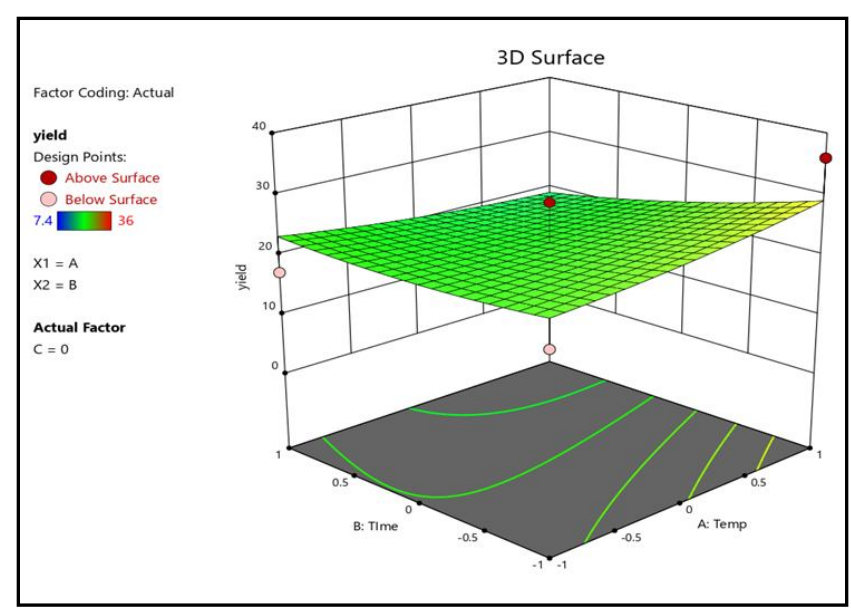

Figure 7b: The response surface diagram for anthelmintic activity with respect to time and temperature.
Optimization of the design at $p<0.05$ considering fast anthelmintic activity and maximum yield has resulted a prediction of desirability 0.878 as presented in Table 9.

Table 9: Predicted design optimization

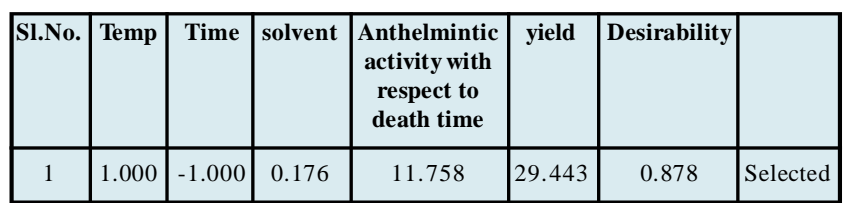

\section{Discussion}

\subsection{Yield of the extract}

Plant bioactive components play important role in various therapeutic activities. The content of phytoconstituents are mainly varied with the extraction procedure and many literatures revealed that microwave oven extraction provides suitable extraction in high selectivity and less time, than any other conventional extraction (Osorio-Tobon, 2020). In the present investigation, methanol extract gave high percentage of yield, followed by aqueous solvent. It was already reported that microwave oven favours polar molecules and solvents with high dielectric constant (Kaufmann and Christen, 2002). Methanol is polar solvent than ethyl acetate and, hence more yield than organic solvent but even more than aqueous solvent. The same result already reported by earlier literature where female Coscinium flower gave higher yield in methanol extract than aqueous when extracted for $25 \mathrm{~min}$ with $10 \mathrm{ml}$ of solvent (Roopashree et al., 2021).

\subsection{Heavy metal estimation}

Determination of heavy metals present in plants are most important aspect for understanding their role in many enzymatic activities in accumulation of bioactive constituents as well as toxicity due to the presence of any unwanted heavy metals. Various elements such as iron $(\mathrm{Fe})$ zinc $(\mathrm{Zn})$, copper $(\mathrm{Cu})$, manganese $(\mathrm{Mn})$, and chromium 
$(\mathrm{Cr})$ are essential nutrients and also important for the physiological and biological functions of the human body. Fe is an essential element in haemoglobin and also helps in porphyrin synthesis, transport of oxygen as well as functioning of the immune system (Rout and Sahoo, 2015). Mn helps in bone and tissue formation, and skeletal growth and also acts as lipid and carbohydrate metabolism regulator (ATSDR, 2012). Cu is essential to maintain metabolism of the human body but in high content leads toxic effect. $\mathrm{Zn}$ is an essential element that plays a key role in plant growth, stabilizing RNA and DNA structure, in maintaining the activity of DNA synthesizing enzymes, helps in accumulation of bioactive compounds especially phenolic constituents, etc. (Kumar et al., 2019). Thereafter, some non-essential heavy metals such as $\mathrm{As}, \mathrm{Hg}, \mathrm{Ni}, \mathrm{Co}, \mathrm{Cd}$ and $\mathrm{Pd}$ are causes toxicity in human body beyond the permissible limits as per WHO guideline. In the present study, these toxic heavy metals are reported as not detected which indicated the safe application of the bark extract.

\subsection{Phytochemical study}

All the extracts were screened for presence of phytoconstituents and revealed methanol extract showed presence of maximum number of phytoconstituents. The identification of phytoconstituents are mainly depends on the solubility of the constituents in the specific solvent. Though, the methanol and aqueous are polar solvents but maximum phytoconstituents are more soluble in methanol than aqueous and other organic solvents (Iloki-Assanga et al., 2015; Dieu-Hien et al., 2019). The same trend also followed in the present study.

\subsection{Total phenolic content}

In the present study, methanol extract showed higher phenolic content than other extracts. Many literatures revealed the content of phenolics showed higher in methanol extract than other solvents (Quy-Diem, et al., 2014; Esmaeili et al., 2015) and the same trend followed in the present investigation. Moreover, it was also evident that microwave oven is more suitable for extraction of phenolic components from the plant parts (Hong et al., 2001; Gallo et al., 2010; Putnik et al., 2015). In this experiment, microwave oven was used for the extraction and estimated high content of phenolics in the methanol extract when extracted for $10 \mathrm{~min}$ at $80^{\circ} \mathrm{C}$. It was also reported that higher temperature increase yield of the extract (Yaakob et al., 2020). The same trend followed in our experiment.

\subsection{Chromatographic study}

TLC was performed for all the extracts based on percentage yield and phenolic content of the extracts. All the extracts $\left(10 \mathrm{~min}\right.$ at $80^{\circ}$ C) showed presence of some components but methanol extract showed presence of phenolic acid, i.e., gallic acid in the selected solvent system (toluene, ethyl acetate and formic acid with the ratio of 7: 5: 1). The same solvent system was used earlier for HPTLC determination of polyphenolic compound from Fenugreek seeds and HPLC estimation of gallic acid from Abutilon indicum leaves respectively, (Laila et al., 2014; Das et al., 2019). Thereafter, HPLC analysis data revealed methanol bark extract gave higher accumulation of gallic acid than other solvents which was the same as the earlier scientific report (Mehta et al., 2017; Das et al., 2019).

\subsection{Anthelmintic activity}

All the extracts were evaluated for anthelmintic activity and resulted higher activity with the methanol extract with respect to death of earthworms in very less time. In the present study, earthworms were selected for the anthelmintic activity due to the physiological similarity between some intestinal round worms infecting man (Awad, 2004). The higher anthelmintic activity was revealed with the increasing in concentration with all the extracts. The plant possesses significant anthelmintic activity due to presence of more polar bioactive phytochemicals such as tannins, phenolics, alkaloids, glycosides, etc., in the polar solvents (Stankovic, 2011). Our study also trend the similar results as reported earlier. Commonly alcoholic extracts are reported for their potent biological activities and inhibits the worms by the efficient release of phenols (Das et al., 2017). The phenolic acid such as gallic acid was identified in CR bark extract and also reported high content of gallic acid in methanol extract than others. The gallic acid helped in the same where many literatures revealed that gallic acid is responsible for anthelmintic activity (Patel et al., 2015).

\subsection{Correlation study}

All the extracts were correlated with percentage yield and percentage phenolic content. The result showed less time with high temperature provided the high content of both and also showed methanol extract revealed high content as compared to others. The correlation showed significantly positive with respect to extracts. The high content of metals is also positively correlated with the extracts. Thereafter, design expert software resulted the polarity of the solvent nearing zero that indicates selection of methanol as extracting solvent, hence the optimized extraction was carried out at $80^{\circ} \mathrm{C}$, for $10 \mathrm{~min}$ with methanol and observed that the prediction was correct and significant based on the investigated results.

\section{Conclusion}

The present study revealed that CR bark has anthelmintic activity. Methanol extract showed higher yield than aqueous and ethyl acetate solvent when extracted with microwave oven extraction using fixed solvent but differed in time and temperature. Thereafter, methanol extract also showed higher content of metals especially $\mathrm{Zn}$ which helps in accumulation of phenolics as bioactive agent in CR bark and showed positive correlation with the yield and percentage of phenolic content. Furthermore, phenolic acid was identified with TLC, HPLC studies and revealed the presence of gallic acid that helped in enhanced anthelmintic activity. Finally, the study was confirmed with statistically tabulated a custom design where significant contribution of temperature and time for yield and anthelmintic activity.

\section{Conflicts of interest}

The authors declare that there are no conflicts of interest relevant to this article.

\section{References}

Alhakmani, F.; Kumar, S. and Khan, S.A. (2013). Estimation of total phenolic content, in vitro antioxidant and anti-inflammatory activity of flowers of Moringa oleifera. Asian Pac. J. Trop. Biomed., 3(8): $623-627$.

ATSDR. (2012). Toxicological profile for manganese. US Department of Health and Human Services, Public Health and Human Services, Centre for Disease Control, Atlanta, Ga, USA

Award, N.E. (2004). Bioactive brominated diterpenes from the marine red alga Jania Rubens (L.) Lamx. Phytother. Res., 18(4):275279. 
Buch, H. and Arya, A. (2017). Antifungal activity of selected plant extracts against three pathogenic fungi of Gossypium herbaceum. Curr. Res. Environ. Appl. Mycol., 7(2):103-108.

Chandrashekhar, C.H.; Latha, K.P.; Vagdevi, H.M. and Vaidya, V.P. (2008). Anthelmintic activity of the crude extracts of Ficus racemosa. Int. J. Green Pharm., 2:100-103.

Das, K.; Rekha, R.; Ibrahim, M.A.; Yahya Ahmed, S. and Dang, R. (2017). Effect of demographic location on Phlebodium decumanum (Willd.) J. Sm. for its phytoconstituents and establishment of antioxidant and novel anthelmintic activity of its aqueous and methanolic leaf extracts. Ann. Phytomed., 6(1):101-106.

Das, K.; Deb, S. and Karanth, T. (2019). Phytochemical screening and metallic ion content and its impact on the antipsoriasis activity of aqueous leaf extracts of Calendula officinalis and Phlebodiumdecumanum in an animal experiment model. Turk. J. Pharma. Sci., 16(3):292-302.

Das, K.; Khan, S.M.; Namratha, N.; Swetha, R. and Gezici, S. (2019). Comparative phytochemical screening, elemental content and chromatographic evaluation for detection and quantification of polyphenolic compounds for strong antioxidant activity of various extracts of Abutilon indicum (Link) Sweet leaves. Ann. Phytomed., 8(1):36-44.

Dieu-Hien, T.; Dinh Hieu, N.; Nhat Thuy. A.T.; Anh Vo, B.; Tuong, H.D. and Hoang Chinh, N. (2019). Evaluation of the use of different solvents for phytochemi-cal constituents, antioxidants, and in vitro antiinflammatory activities of Severinia buxifolia. Journal of Food Quality: ID 8178294, https://doi.org/10.1155/2019/8178294.

Esmaeili, A.K.; Taha, R.M.; Mohajer, S. and Banisalam, B. (2015). Antioxidant activity and total phenolic and flavonoid content of various solvent extracts from in vivo and in vitro grown Trifolium pretense L. Biomed Res. Internation. 2015: Article ID 643285, https:// doi.org/10.1155/2015/643285.

Gallo, M.; Ferracane, R.; Graziani, G.; Ritieni, A. and Fogliano, V. (2010). Microwave assisted extraction of phenolic compounds from four different spices. Molecules, 15(9):6365-6374.

Girotra, P. and Singh, S.K. (2013). The therapeutic efficacy of katira gum in burn injury healing. World J. Pharm. Res., 2(6):2587-2595.

Hong, N.; Yaylayan, V.A.; Raghavan, G.S.V.; Paré, J.R.J. and Bélanger, J.M.R. (2001). Microwave assisted extraction of phenolic compounds from grape seed. Nat. Prod. Res., 15:197-204.

Hongsing, P.; Palanuvej, C. and Ruangrungsi, N. (2012). Chemical compositions and biological activities of selected exudate gums. J. Chem. Pharm. Res., 4(9):4174-4180.

Ibrahim, M.H.; Kong, Y.C. and Zain, N.A.M. (2017). Effect of cadmium and copper exposure on growth, secondary metabolites and antioxidant activity in the medicinal plant Sambung Nyawa (Gynura procumbens (Lour.) Merr). Molecules. 22:1623; doi:10.3390/ molecules22101623.

ICH Harmonised Tripartite Guideline. (2005). Q2 (R1): Validation of Analytical Procedures: Text and Methodology Current Step 4 versions.

Iloki-Assanga, S.B.; Lewis-Luján, L.M.; Lara-Espinoza, C.L.; Gil-Salido, A.A.; Fernandez-Angulo, D.; Rubio-Pino, J.L. and Haines, D.D. (2015). Solvent effects on phytochemical constituent profiles and antioxidant activities, using four different extraction formulations for analysis of Bucida buceras L. and Phoradendron californicum . BMC Res Notes. 8:396. https://doi.org/10.1186/s13104-015-1388-1.

Kaufmann, B. and Christen, P. (2002). Recent extraction techniques for natural products: microwave-assisted extraction and pressurized solvent extraction. Phytochem. Anal., 13:105-113.
Kawde,A.B.; Batra, R.J.; Weginwar, R.G.; Akkewar, D.M.; Gond, G.S. and Aparna, Y. (2015). Preliminary phytochemical screening and bioevaluatuion studies of stem bark of Cochlospermumgossypium. International Journal of Researches in Biosciences, Agriculture and Technology, 1:199-206.

Kokate, C.K. (2005). A textbook of practical pharmacognosy. Vallabh Prakashan, 5 ${ }^{\text {th }}$ Edition. pp:105-111.

Kumar, V.; Okem, A.; Moyo, M.; Gruz, J.; Dolezal, K. and Van Staden, J. (2019). Effect of zinc on the production of phenolic acids and hypoxoside in micropropagated Hypoxis hemerocallidea. Plant Growth Regul., 98:19-24.

Laila, O.; Murtaza, I.; Abdin, M.Z.; Ahmad, S.; Ganai, N. S. and Jehangir, M. (2014). Development and Validation of HPTLC Method for Simultaneous Estimation of Diosgenin and Quercetin in Fenugreek Seeds (Trigonella foenum-graceum). International Scholarly Research Notices. Article ID 583047. 8 Pages. http://doi.org/ $10.1155 / 2014 / 583047$.

Mehta, S.; Singh, R.P. and Saklani, P. (2017). Phytochemical screening and TLC profiling of various extracts of Reinwardtia indica. Internation. J. Pharmacog. Phytochem. Res., 9(4):523-527.

Osorio-Tobon, J.F. (2020). Recent advances and comparisons of conventional and alternative extraction techniques of Phenolic compounds. J. food Sci. Technol. 57:4299-4315. http://doi.org/ 10.1007/s13197-020-04433-2.

Panda, S.K.; Mohanta, Y.K.; Padhi, L.; Park, Y.; Mohanta, T.K. and Bae, H. (2016). Large scale screening of ethnomedicinal plants for identification of potential antibacterial compounds. Molecules, 21:293.

Patel, A.A.; Amin, A.A.; Patwari, A.H. and Shah, M.B. (2017). Validated high performance thin layer chromatography method for simultaneous determination of quercetin and gallic acid in Leea indica. Revista Brasileira de Farmacognosia., 27:50-53.

Patel, M.; Ganeshpurkar, A.; Bansal, D. and Dubey, N. (2015). Experimental evaluation of anthelmintic effect of gallic acid. Pharmacog. Communications, 5(2):145-147.

Ponnamma, P.; Manasa, G.; Sudarshana, M.S.; Murali, M. and Mahendra, C. (2017). In vitro antioxidant, antibacterial and phytochemical screening of Cochlospermum religiosum (L.) Alston - A potent medicinal plant. Tropic. Plant Res., 4(1):13-19.

Puskuri, J.; Katukam, V. and Sashidhar, R.B. (2017). Immunological evaluation of Gum kondagogu (Cochlospermum gossypium): A tree gum with potential applications in food and pharma industry. Bioact. Carbohydr. Diet. Fibre, 11:48-52.

Putnik, P.; Bursać Kovačević, D.; Penić, M. and Dragović-Uzelac, V. (2015). Optimizing microwave-assisted extraction parameters for polyphenols recovery from sage (Salvia officinalis L.). Ann Nutr Metab. 67(1):523-524.

Quy-Diem, D.; Artik Elisa,A.; Phuong Lan Tran, N.; Lien Huong, H.; Felycia Edi, S.; Suryadi, I. and Yi-Hsu, J. (2014). Effect of extraction solvent on total phenol content, total flavonoid content, and antioxidant activity of Limnophila aromatic. J. Food and Drug Anal., 22(3): 296-302.

Roopashree, T.S.; Das, K.; Prashanth, N. and Rakesh Kumar, K. (2021). Pharmacognostic and chromatographic evaluation of male and female flowers of Coscinium fenestratum for Berberine content and its effect on antioxidant activity. Thai J. Pharma. Sci., 45(2): $155-164$.

Rout, G.R. and Sahoo, S. (2015). Role of iron in plant growth and metabolism. Reviews in Agricultural Science, 3:1-24. doi: 10.7831/ ras.3.1. 
Sasikala, A.; Linga Rao, M.; Savithramma, N. and Prasad, T.N.V.K. V. (2015) Synthesis of silver nanoparticles from stem bark of Cochlospermum religiosum (L). Alston: An important medicinal plant and evaluation of their antimicrobial efficacy. Appl Nanosci., 5:827835 .

Satpure, S.S. (2017). A study on ethnomedicinal plants of Bhadravati tahsil, dist. Chandrapur, Maharashtra. International Journal of Informative and Futuristic Research, 4(12):8633-8641.

Savithramma, N.; Yugandhar, P.; Babu, H.R. and Prasad, S.K. (2014). Validation of indigenous knowledge of Yanadi tribe and local villagers of Veyilingalakona: A sacred grove of Andhra Pradesh, India. J. Pharm. Sci. Res., 6(11):382-388.

Stankovic, M.S. (2011). Total phenolic content, flavonoid concentration and antioxidant activity of Marrubium peregrinum L. extracts. Kragujevac Journal of Science, 33:63-72.

Suneetha, J.; Prasanthi, S.; Naidu, R.B.V.A. and Reddi, S.T.V.V. (2011). Indigenous phytotherapy for bone fractures from Eastern Ghats, Andhra Pradesh. Indian J. Tradit. Know, 10(3):550-553.
Swathi, B.G.; Smruthi, B.S.; Banu, S. and Kekuda, P.T.R. (2019). Insecticidal, antimicrobial and antioxidant activity and elemental analysis of Cochlospermum religiosum (L.) Alston (Bixaceae). J. Drug Delivery Ther., 9(2):422-428.

Vinod, V.T.P.; Sashidhar, R.B.; Sarma, V.U. and Vijaya Saradhi, U.V.(2008). Compositional analysis and rheological properties of gum kondagogu (Cochlospermum gossypium): A tree gum from India. J. Agric. Food Chem., 56(6):2199-2207.

Vinod, V.T.P. and Sashidhar, R.B. (2011). Bioremediation of industrial toxic metals with gum kondagogu (Cochlospermum gossypium): A natural carbohydrate biopolymer. Indian J. Biotechnol., 10:113120 .

Yaakob, M.N.A.; Roslan, R.; Salim, N.; Mustapha, S.N.H.; Zakaria, S.; Chia, C.H.; Sajab, M.S. and Yuh, P.Y.N. (2020). Effect of temperature on the yield of lignin extracted using microwave-assisted acetosolv from Empty Fruit Bunch Fibers. Materials Science Forum, 981:240-244.

Sravani Singirikonda, Kuntal Das, Sayani Bhattacharyya, M. Saifulla Khan and Sonam Singh (2021). Effect of 